\title{
Business Model challenges for Cab aggregators: A Case Study of Ola
}

\author{
Robin Singh \\ Digital Marketing Consultant, TCS, India \\ Singh345.robin@blore.tcs.co.in
}

\begin{abstract}
This research discusses the business model challenges faced by cag aggregator platform models in developing countries. Technology-based platforms have been disrupting traditional businesses and rewriting the rules of the game. Ola cabs has been instrumental in shaping the Indian platform business landscape in a big way. Using case methodology, the author analyses the situation and business model to present the salient features of Ola's model. However, this paper also puts the spot light on the inherent challenges in this model and warns the need for continuous business model innovation and service quality.
\end{abstract}

\section{Introduction}

Ola cabs business model was that of a market place aggregator which used technology to disrupt the existing system of taxi services and radio taxi operators to help customers connect with all types of cabs and car rentals. The market in India was largely unorganised but for a few radio taxi service providers who were struggling to reach break-even (Tripathy and Leesa, 2017). Most of the general car rental and private taxi operators were unprofessional and provided little amenities to customers in terms of technology interface in booking or providing information on cabs, its condition and many over charged customers by 
intentionally taking long routes (for customers who were not familiar with the place) or for waiting charges. Generally non-availability of services at wee hours was also a serious issue that a common customer faced.

Ola cabs uses a market place model and does not own a fleet of cabs unlike typical radio taxi operators (Kashyap and Bhattia, 2018). A customer can compare the different rates offered by various operators and can choose to book a cab which satisfies him. Also, it allows one to rent a car for outstation trips or can hire one for local ride which is charged on an hourly rate .

\section{Background of can aggregation platform model}

Aggregator model has been a disruptive innovation bought by internet companies and was accelerated by the surge in smart phones and wider use of online payment facilities (Adityan et al., 2017). Like elsewhere in the world this model has seen emergence of travel aggregator makemytrip.com, redbus.in, movie ticket aggregator bookmyshow.com, online commerce sites flipkart.com and snapdeal .com etc. Leveraging the aggregation model, these companies have redefined the traditional way business was done in respective categories by redrawing industry structure in their favour.

Cab aggregation, even globally, is a recent phenomenon and solid business models have not yet emerged. $\mathrm{Cab}$ aggregation companies connected taxi operators or drivers with a large number of customers by giving them better chances for effectively utilising their otherwise depreciating asset. Using web based and mobile based technology, aggregators improved the driver's chances of plying more trips per day (Anirvinna and Deshmukh, 2019). On the other hand customers were assured of competitive rates and accurate billing, enhanced safety 
since cabs can be tracked real-time and driver identity is known. Customer is empowered in an unprecedented way as he can opt for informed choice in a much more convenient way.

There has been many instances in India were Radio taxi association came out against aggregators and demanded government interference to regulate them. The key issue was aggregators could freely change taxi fares and had low operations cost as they did not own fleet. Many drivers employed by traditional cabs and radio taxi operators found aggregators like Ola cabs and Uber more attractive thanks to the seemingly higher earning potential.

\section{Ola Cabs Business model and Critical Success Factors}

\section{Operations and Service Delivery}

A customer has the following options to book a cab. He can use the website or contact the 24 X7 call centre using a hotline like what typical radio taxis provide, or can also book through a mobile app which uses the GPS and Google maps facility to alert the nearest cabs in the locality (Pandya et al., 2017).

Ola Cabs is the largest mobile apps based cab aggregator and has well above 33,000 cabs appearing on its app for customers to choose from. They can view, book and track a cab in real-time (Kalla and Purohit, 2015).

A customer need not register or must have an account to book either or avail full service. Customers is allowed to book a cab later by using the advance setting for a future date and time as well. The company allows full refund if the booked vehicles do not show up and in 
case of delay in arrival company allows the customer to exercise an option to request for an alternative cab or refund. Also, customer can go for a cancellation 48 hours before the journey and $50 \%$ refund if he opts for cancellation before 24 hours of the advance payment.

Its website OlaCabs .com is comprehensive site which not only helps customer to book the service but also provides comparison across different operators, price, facilities etc at the same time giving lots of information through its blogs on topics like upcoming festivals and other tourist attractions, to customers and on vehicle maintenance etc to drivers through its blogs and social media updates. Customers can access information on different services and cabs by taking a peep into what is available with each cabs, be it the presence of video screens ,news papers, general quality or cleanliness.

The company like other taxi aggregators has been following an 'asset-light 'model where it does not go for cab ownership which needs investment in ownership and regular maintenance costs.

Ola Cabs business model which treats its drivers as 'empowered entrepreneurs. A driver can attach his vehicle to the company after a verification process and five days of training in which basic etiquettes and customer service precepts are introduced along with operational nitty-grittys. Once joined the network, cab sports the company signage and a smart phone with Ola Cabs (given by the company against a deposit) mobile app software doubles up as the interface between company base station and the cab driver.This smart phone interface, pre-loaded with the app, helps driver to calculate fares and distance travelled and makes use of Google maps and GPS facility in the phone to get directions to the customer location. A customers request is viewed by all logged in drivers in the near by locality and interested drivers can accept the request. Once acceptance is given company shares details of the 
customer and pick up location. Mobile app at the drivers end allots the cabs that is helps in connecting the right cab to the customer based on his acceptance of the request and proximity to the customer's pick up location. The navigation facility in the mobile app make use of Google Maps and GPS based navigation to help the driver reach the customer location as well

Though the driver joins the network he is free to run on his own whenever the cabs find free time. This facility addressed one of the big problems of under utilisation of the vehicle which typical radio taxi drivers faced. Most of Them were not allowed to do any trips on their own and on average a taxi driver could make only about 5 metered trip. That is on an average forgetting about four to five hours of trips he has to be on the road for ten to eleven hours.

Ola cabs keeps $10-20 \%$ of the metered charge for every trip the driver makes after he logs into the Ola Cabs software. Maintenance and periodic service is undertaken by the cab owner. For giving access to technology platform, they charge a small fee as well from operators.

For an operator the revenue model will be as follows. The expenses will be approximately INR 40,000, out of this INR 15,000 may go for the EMI (equated monthly instalment) to the financier if the vehicle is bought on loans and about INR 7000-9000 as fuel cost. The service and maintenance will be about INR 4000-5000. A driver may pocket INR 10,000 to INR 15,000 as his salary. A cab runs approximately 1,500 kilo meters per month.

The company has understood that the for the success of this model driver is an important partner in the scheme of things. He is the person who delivers the service and standardisation of delivery depends on driver sophistication and efficiency that is imparted through training. 
Ola cabs has recently started initiatives to retain drivers by providing incentives if a driver runs more trips and earns more revenue. The company also gives fringe benefits in the form of reimbursement for families of drivers for medical expenses incurred. In yet another scheme free education is offered for the children of the drivers who get best rating in performance assessment .

Given below are the distinct features which make Ola Cabs different from private taxi operators

\section{Price Transparency}

In the aggregation model Ola Cabs offers ultimate transparency on different operators and their pricing or hourly charges. This helps a prospective passenger to make a right decision as information asymmetry is eliminated and the power to choose is with the buyer. The market place witnessed a shift from sellers market to buyer's market.

\section{Technology}

Ola Cabs is a technology provider and that is the competency unlike radio taxi operators. They run and control the back end in which they are competent while managing and maintaining the cab is the drivers business. Websites and apps development and managing calls and connecting a needy customer to a driver who is ready and to serve is left to Ola Cabs. Managemnt of software, IT systems, servers and call entre were the typical functions which brought about competency. 


\section{Operations}

Fleet optimisation, customer allotment and call centre management are the important tasks that needs to be taken care of. Managing available inventory and expanding it while striking a balance between demand and supply with insights from analytics is a critical success factor for a cab aggregator.

Company needs to do sourcing so that it can add more number of cab operators and cabs in its network. The city manager typically manages the operators and make sure that smooth relationship exist between Ola cabs and operators. This is an important activity which will ultimately lead to the retention of operators in a competitive market.

\section{Branding and Marketing}

It was a boon for small operators and individual cabs drivers to get their service under the umbrella brand (Saju et al., 2017). They benefited from the corporate branding done by the aggregators and resulted in instant brand recognition and recall by customers. It was comfort factor for the customers as well, since the emergence of branded and well recognised player in the highly fragmented and unorganised taxi/cab rental market (Saju et al., 2018). Olacabs uses its website and Social media to listen to customers and engages in learning from conversations and feedbacks. Social media is used to enhance brand communication as well. It also advertises in local mass media including FM radio stations. However, the advertising efforts always reach the much visible levels around the time of its launch in a city.

By January 2014, Ola cabs hiked their advertising on national media including sponsoring TV shows and events. They also hiked spent on national print media and enhanced digital presence through display and banner ads on popular sites besides search engine marketing 


\section{Customer feed back}

Unlike private taxi operators customer can post a feed back on the website or on social media about the perator for his delay in turning up or ride quality, driver behaviour, vehicle condition or any other pain points (Manjunath, 2015).This feed back and constant listening to customer conversations opens up the avenue to co create service innovations with customers without much effort .

\section{Quality Audits}

The company conducts audits and check to make sure that variability in service quality is eliminated as far as possible. It conducts a thorough audit of the vehicle before the cab is listed on its website. Once the cab meets the bench mark the driver imparted soft skills enhancement and customer service etiquettes (Surie and Kodunganti, 2016). Once the operations kick starts company undertakes random audits to make sure that the previous standards on quality and service delivery is well maintained.

\section{Surge pricing}

This dynamic pricing tactic was introduced globally by taxi hailing app Uber. In this model, charges vary on an hourly basis, based on real time fluctuations in demand and supply (Wang et al., 2016). During peak hours the rates go up almost 3 times and this made Uber a very popular choice of many drivers.

Ola Cabs also tried this model in four metros (Mumabi, Delhi, Bangalore and Chennai) with variation to take advantage of the regulatory loops holes regarding taxi aggregator business model. In India taxi rates vary as we move from one state to another. Radio cabs rates were set up by the state regulator and their metres were calibrated once an year. Hence surge 
pricing was not possible for them. But for aggregators like Ola cabs who were not covered by such regulation could exercise dynamic pricing (Kowsalya, 2018). Ola Cabs used different pricing for Standard and Prime services and apart from this surge pricing was introduced during peak hours when demand would rise and supply would come down. During peak hours, $7 \mathrm{am}$ to10am and $4 \mathrm{pm}$ to $7 \mathrm{pm}$ it charges a flat INR 50 on its services in addition to the normal rates.

\section{Use of Analytics}

Being a technology provider, use of analytics has been critical for the company. It used optimisation models and real time analytics to predict and control demand and supply conditions (Pandya et al., 2017). For instance, analytics provides insight into traffic bottlenecks and approximate time for a cab to reach a customer or drop him off to destination, condition of the roads, time of the day and locations where demand is more (Mishra and Raj, 2017). With better use of analytics company should be able to effectively utilise the idle time of the drivers to match available inventory with the surging demand. It is also noteworthy that across the board about one fifth of total customer requests could not be accommodated by radio taxis and aggregators. Also analytics could give insight on driver behaviour and productivity. It can also keep track of customers and can use CRM based analysis to segregate and reward profitable and loyal customers.

\section{Challenges For Ola}

a) Need for continuous business model innovation

b) The need for licenced drivers. Road infrastructure. Regulatory issues.

c) Wafer thin margins 
d) Operators will stick in if steady business come in and customer will stick if service level goes up

e) Driver behaviour

f) One fifth of the booking can not be accommodated

g) $100 \%$ service quality if you have control over drivers and opeartaors (Saju and Rajan, 2014)

\section{Conclusion}

The aggressive nature of cab aggregation platform expansion business by rivals has been challenging for Ola. They need to invest in a host of services to transform and succeed in the market. Business model innovation, background checks and service quality are most important.However, the road ahead will be a tough one thanks to the COVID-19 pandemic.

\section{References}

Adityan, H., Harikrishnan, K., Anand, S. J. J., \& Saju, B. (2017). Innovativeness and uniqueness as motivations for online shopping tendency and the mediating role of information acquisition. International Journal of Business Innovation and Research, 13(1), $30-51$.

Anirvinna, C., and Arun Kumar Deshmukh. "Pricing strategy of cab aggregators in India." Journal of Revenue and Pricing Management (2019): 1-7. 
Kalla, N., \& Purohit, H. (2017). Designing Service Offering in the E-Marketing Era: A Case Study of OLA Cabs. International Journal on Customer Relations, 5(1), 1.

Kashyap, R., \& Bhatia, A. (2018). Taxi drivers and taxidars: a case study of Uber and Ola in Delhi. Journal of Developing Societies, 34(2), 169-194.

Kowsalya, K. (2018). A study on the marketing stategies of OLA. South Asian Journal of Marketing \& Management Research, 8(12), 38-40.

Manjunath, G. (2015). Brand Awareness and Customers Satisfaction towards OLA Cabs in Bengaluru North and South Region.

Mishra, T., \& Raj, G. (2017, January). QoS implementation in Web Services selection and ranking using data analysis. In 2017 7th International Conference on Cloud Computing, Data Science \& Engineering-Confluence (pp. 537-542). IEEE.

Pandya, U., Rungta, R., \& Iyer, G. (2017). Impact of use of mobile app of OLA cabs and TAXI for sure on Yellow and Black cabs. Pacific Business Review International, 9(9), 91105.

Saju, B., Rangarajan, K., Harikrishnan, K., \& Anand, S. J. J. (2017). New insights on consequences of corporate associations-an investigation of mediators and moderator in Indian context. International Journal of Business Excellence, 12(1), 102-126.

Saju, B., Harikrishnan, K., \& Anand, S. J. J. (2018). Modeling brand immunity: the moderating role of generational cohort membership. Journal of Brand Management, 25(2), 133-146. 
Surie, A., \& Koduganti, J. (2016). The emerging nature of work in platform economy companies in Bengaluru, India: The case of Uber and Ola Cab drivers. E-Journal of International and Comparative Labour Studies, 5(3).

Tripathy, A., \& Leepsa, N. M. (2017). Ola Consolidating to Dominate the Cab Hiring Market. Journal of Case Research, 8(01).

Wang, X., He, F., Yang, H., \& Gao, H. O. (2016). Pricing strategies for a taxi-hailing platform. Transportation Research Part E: Logistics and Transportation Review, 93, 212231. 
